Polymer Journal, Vol. 9, No. 2, pp 145-151 (1977)

\title{
Molecular and Crystal Structure of Hexafluoroacetone-Ethylene Alternating Copolymer
}

\author{
Hajime Matsubayashi, ${ }^{*}$ Yozo Chatani, ${ }^{*}$ Hiroyuki Tadokoro, \\ Yoneho TABATA, ${ }^{* *}$ and Wataru ITo** \\ *Department of Polymer Science, Faculty of Science, Osaka University, \\ Toyonaka, Osaka 560, Japan. \\ **Department of Nuclear Engineering, University of Tokyo, \\ Hongo, Bunkyo-ku, Tokyo 113, Japan.
}

(Received November 1, 1976)

\begin{abstract}
The copolymer obtained by radiation-induced copolymerization of hexafluoroacetone with ethylene at $-78^{\circ} \mathrm{C}$ was examined by $\mathrm{X}$-ray diffraction. The crystal data are: orthorhombic, $\mathrm{P} 2{ }_{1} 2_{1} 2_{1}, a=10.63 \mathrm{~A}, b=8.00 \mathrm{~A}, c$ (fiber axis) $=8.01 \mathrm{~A}$, and two polymer chains pass through the unit cell. The copolymer was revealed to have an alternating structure of hexafluoroacetone and ethylene units. The molecular chain forms a $(2 / 1)$ helix of essentially $(T T T C)_{2}$ conformation. The internal rotation angles are as follows:

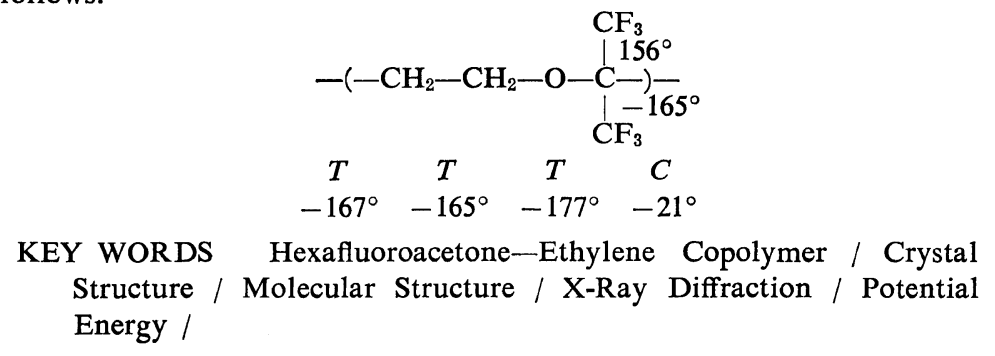

In a previous paper, ${ }^{1}$ copolymerization of hexafluoroacetone with several $\alpha$-olefins by $\gamma$ irradiation was reported. In particular, it was concluded from elementary analysis, NMR, and infrared spectra that the hexafluoroacetoneethylene copolymers obtained below the critical polymerization temperature, $-10^{\circ} \mathrm{C}$, should have an alternating structure of both components over a wide range of monomer concentration of the component in monomer mixtures.

The purpose of the present X-ray study is primarily to give additional strong evidence for the alternating structure. If the copolymer has the alternating structure, it is considered to be a derivative of poly(oxacyclobutane), $\left(-\mathrm{CH}_{2}-\right.$ $\left.\mathrm{CH}_{2}-\mathrm{CH}_{2}-\mathrm{O}-\right)_{n}$. Another purpose is, therefore, to determine the molecular and crystal structures, and to compare them with those of three crystalline forms of poly(oxacyclobutane) and of two forms of poly[3,3,-bis(chloromethyl) oxacyclobutane], which is also a derivative of poly(oxacyclobutane) possessing bulky side groups $-\mathrm{CH}_{2} \mathrm{Cl}$.

\section{EXPERIMENTAL}

\section{Sample}

The sample used in this study was the copolymer obtained by $\gamma$-irradiation of a hexafluoroacetone-ethylene mixture at $-78^{\circ} \mathrm{C}$. The mole ratio of hexafluoroacetone to ethylene in this polymer was estimated from elementary analysis to be $1.000: 0.990$. The melting point of this polymer, measured by using a polarizing microscope, was $100^{\circ} \mathrm{C}$. A uniaxially oriented specimen of diameter $0.25 \mathrm{~mm}$ was made by stretching at about $-20^{\circ} \mathrm{C}$ after quenching of the melt in dry ice-methanol and annealed at $75^{\circ} \mathrm{C}$ for $10 \mathrm{hr}$. Hereafter the polymer is abbreviated as poly(HFAc-ET).

$X$-ray Measurement

X-Ray measurements for poly(HFAc-ET) 


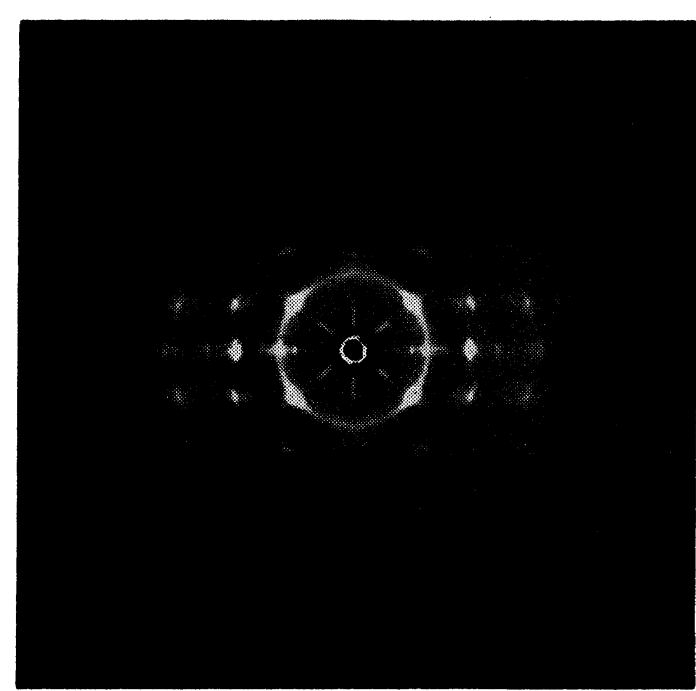

Figure 1. X-ray fiber photograph of poly(HFAcET).

were made by using nickel-filtered $\mathrm{CuK} \alpha$ radiation. A cylindrical camera of $3.5-\mathrm{cm}$ radius was used for taking the fiber photograph. The fiber photograph of poly(HFAc-ET) is shown in Figure 1. The calibration of Bragg angles was carried out with reference to those of aluminum powder. Intensities of thirty reflections obtained by the multiple film method were measured by visual comparison with a standard intensity scale and were corrected for the single-crystal rotation Lorentz-polarization factor. The Weissenberg photograph was taken by setting the uniaxially oriented specimen with the fiber direction perpendicular to the camera axis, and was used to find the systematic absences of the $00 l$ meridional reflections.

\section{STRACTURE ANALYSIS}

\section{Unit Cell and Space Group}

All the observed reflections could be indexed by an orthorhombic cell with parameters $a=$ $10.63 \mathrm{~A}, b=8.00 \mathrm{~A}$, and $c$ (fiber axis) $=8.01 \mathrm{~A}$. The space group was determined as $\mathrm{P} 2_{1} 2_{1} 2_{1}$ by the systematic absences of these reflections: h00: $h=2 n+1 ; 0 k 0: \quad k=2 n+1 ; 00 l: l=2 n+1$. By assuming that four (hexafluoroacetone + ethylene) units are contained in the unit cell, the density was calculated as $1.89 \mathrm{~g} / \mathrm{cm}^{3}$, which is reasonable in comparison with the observed density, $1.78 \mathrm{~g} / \mathrm{cm}^{3}$, measured by the flotation method in an ethylene bromide-carbon tetrachloride mixture at $30^{\circ} \mathrm{C}$.

\section{Molecular Models}

By taking into account the fiber period $8.01 \mathrm{~A}$, the space group $P 2_{1} 2_{1} 2_{1}$, and the $1: 1$ mole ratio of hexafluoroacetone to ethylene units, it was clear that poly(HFAc-ET) is an alternating copolymer and that there exist two equivalent molecular chains of twofold helix in the unit cell.

In order to find the most reasonable molecular model, the intramolecular potential energy was calculated for the alternating copolymer with (2/1) helical symmetry and the observed identity period. The internal rotation angles about the $\mathrm{C}-\mathrm{C}\left(\mathrm{F}_{3}\right)$ bonds were fixed for simplicity as the staggered position. Therefore, the independent variables which determine the conformation are the two internal rotation angles of the main chain. $^{2}$ In the calculation, internal rotation barriers, van der Waals interactions, and electrostatic interactions were taken into account in a similar manner to that used in a previous work. ${ }^{3}$ The sinusoidal function was used for internal rotation barriers, and the LennardJones 6-12 function for van der Waals interactions. Electrostatic interactions were calculated under the point dipole approximation. The potential parameters used were essentially similar to those reported in ref 3 , except for those for the $F$ atom. The values of the van der Waals radius and the atomic polarizability for the $F$ atom were taken from ref 4 and 5 , respectively. The effective number of the outershell electrons was estimated to be 7.7, according to the procedure of ref 6 , by using the data of ref 7. The value of the $\mathrm{C}-\mathrm{F}$ bond moment was assumed to be $1.41 \mathrm{D}^{8,9}$ The molecular dimensions used in this calculation are as follows: $\mathrm{C}-\mathrm{C}=1.54 \mathrm{~A} \mathrm{C}-\mathrm{O}=1.43 \mathrm{~A}, \mathrm{C}-\mathrm{F}=$ $1.34 \mathrm{~A}, \mathrm{C}-\mathrm{H}=1.09 \mathrm{~A}$, and all the bond angles= $109.5^{\circ} .^{10,11}$ Three molecular models I, II, and III, which correspond to the potential minima, were selected. They are shown in Figure 2; their internal rotation angles and potential energies are listed in Table I.

\section{Crystal Structure Determination}

The three starting models were examined by 

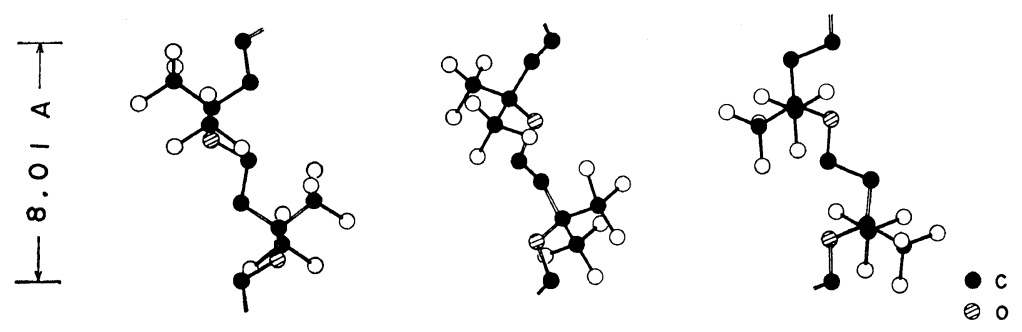

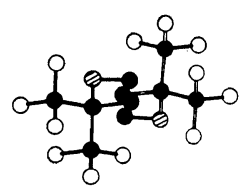

Model I

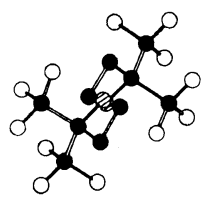

Model II

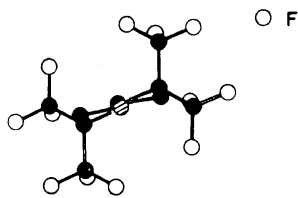

Model III

Figure 2. Three molecular models of poly(HFAc-ET).

Table I. Internal rotation angles and intramolecular potential energies of molecular models

\begin{tabular}{lrrrrc}
\hline & \multicolumn{1}{c}{$\tau_{1}{ }^{\mathrm{a}}{ }^{\circ}$} & \multicolumn{1}{c}{$\tau_{2^{\mathrm{a}}}{ }^{\circ}$} & \multicolumn{1}{c}{$\tau_{3^{\mathrm{a}}}{ }^{\circ}$} & \multicolumn{1}{c}{${ }^{\circ}{ }^{\mathrm{a}}{ }^{\circ}$} & $E, \mathrm{kcal} / \mathrm{mol} \mathrm{m} . \mathrm{u}$. \\
\hline Model I & $172(T)$ & $116(S)$ & $50(G)$ & $154(T)$ & 13.1 \\
Model II & $120(S)$ & $168(T)$ & $160(T)$ & $48(G)$ & 15.1 \\
Model III & $-174(T)$ & $-165(T)$ & $-160(T)$ & $-22(C)$ & 15.9 \\
\hline
\end{tabular}

a Numbering of internal rotation angles are as follows:

$$
-\left[-\mathrm{CH}_{2}-\mathrm{CH}_{\tau_{1}} \tau_{\tau_{2}} \tau_{\tau_{3}}-\mathrm{C}\left(\mathrm{CF}_{3}\right)_{2}-\right]-\mathrm{CH}_{4}-
$$

packing so that the chain axis coincided with a two-fold screw axis parallel to the $c$ axis. There remained two parameters to be determined, i.e., the angular disposition of the chain about the chain axis and the chain height along the fiber axis. Although models I and II gave lower intramolecular potential energies than model III, a trial-and-error procedure in structure factor calculation rejected models I and II because of insufficient agreement between the observed and calculated intensities; the calculated intensities for the most intense reflection on the equator were only one-third of the observed value. Only model III thus remained as a possible model. The constrained leastsquares method ${ }^{12,13}$ was then applied to refinement of a crystal model which gave the most plausible packing of molecular model III; the discrepancy factor $R=\Sigma\left|\sqrt{I_{\mathrm{o}}}-\sqrt{I_{\mathrm{c}}}\right| / \Sigma \sqrt{I_{\mathrm{o}}}$ was 0.28 . Throughout the refinement the values of the bond lengths and bond angles were fixed in the same manner as in the potential energy calculation. The bond length and bond angles between the successive asymmetric units were retained at the aforementioned values by constraining the distances between appropriate atoms, using five Lagrange undetermined multipliers (see footnote of Table II). The parameters refined were thus a scale factor, an overall isotropic temperature parameter, three fractional coordinates of a fluorine atom chosen as the origin of the coordinate system fixed on the molecule, three Eulerian angles, and four internal rotation angles. The hydrogen atoms were neglected for simplicity. The final discrepancy factor was 0.17 for the observed independent 25 reflections. The final parameters are listed in Table II, and the fractional atomic coordinates derived from the final parameters are listed in Table III. Table IV gives the comparison between the observed and calculated spacings and intensities. The crystal structure is shown in Figure 3. The molecular chains make contact with each other reasonably through the side groups and the interchain atomic distances are close to the 
H. Matsubayashi, Y. Chatani, H. Tadokoro, Y. Tabata, and W. Ito

Table II. Final parameters and their standard deviations obtained by least-squares refinement ${ }^{\mathrm{a}}$

\begin{tabular}{|c|c|c|c|}
\hline Parameter & & Valve & $\begin{array}{l}\text { Standard } \\
\text { deviation }\end{array}$ \\
\hline $\begin{array}{l}\text { Overall temperature } \\
\text { parameter }\left(\mathbf{A}^{2}\right)\end{array}$ & & 16.7 & 1.9 \\
\hline \multirow[t]{3}{*}{ Eulerian angles, ${ }^{\circ}$} & $\theta$ & 55.6 & 5.0 \\
\hline & $\phi$ & -36.5 & 3.9 \\
\hline & $\chi$ & -50.4 & 2.9 \\
\hline \multirow{3}{*}{$\begin{array}{l}\text { Fractional coordinates } \\
\text { of the origin atom } F(1)\end{array}$} & $x$ & 0.394 & 0.009 \\
\hline & $y$ & 0.409 & 0.009 \\
\hline & $z$ & 0.316 & 0.017 \\
\hline \multicolumn{4}{|l|}{ Internal rotation angles, ${ }^{\circ}$} \\
\hline$F(1)-C(1)-C(2)-C(3)$ & & 75.0 & 6.2 \\
\hline$C(1)-C(2)-C(3)-F(4)$ & & 156.4 & 6.4 \\
\hline$C(1)-C(2)-O-C(4)$ & & -56.4 & 4.9 \\
\hline$C(2)-0-C(4)-C(5)$ & & -164.6 & 4.1 \\
\hline
\end{tabular}

- Atoms are numbered as follows:

$$
\begin{aligned}
& F(2)- \stackrel{C}{C}(1)-F(3) \\
&-C(5)-C(4)-0-C(2)-C^{\prime}(5)-C^{\prime}(4)- \\
& F(5)-C(3)-F(6) \\
& ! \\
& F(4)
\end{aligned}
$$

Fixed distances between successive chain units are $\quad 0 \cdots \mathrm{C}^{\prime}(5)=2.43 \mathrm{~A}, \quad \mathrm{C}(2)-\mathrm{C}^{\prime}(5)=1.54 \mathrm{~A}$, $C(2) \cdots C^{\prime}(4)=2.51 \mathrm{~A}, \quad C(3) \cdots C^{\prime}(5)=2.51 \mathrm{~A}$, and $C(1) \cdots C^{\prime}(5)=2.51 \mathrm{~A}$.

Table III. Atomic parameters in fractional coordinates $^{\mathrm{a}}$

\begin{tabular}{lrrr}
\hline & $x$ & $y$ & \multicolumn{1}{c}{$z$} \\
\hline $\mathrm{F}(1)$ & 0.394 & 0.409 & 0.316 \\
$\mathrm{C}(1)$ & 0.373 & 0.269 & 0.228 \\
$\mathrm{C}(2)$ & 0.266 & 0.170 & 0.309 \\
$\mathrm{E}(3)$ & 0.139 & 0.255 & 0.271 \\
$\mathrm{~F}(4)$ & 0.046 & 0.143 & 0.282 \\
$\mathrm{O}$ & 0.265 & 0.003 & 0.244 \\
$\mathrm{C}(4)$ & 0.254 & 0.009 & 0.066 \\
$\mathrm{C}(5)$ & 0.216 & -0.164 & -0.009 \\
$\mathrm{~F}(2)$ & 0.341 & 0.310 & 0.071 \\
$\mathrm{~F}(3)$ & 0.478 & 0.176 & 0.225 \\
$\mathrm{~F}(5)$ & 0.120 & 0.379 & 0.380 \\
$\mathrm{~F}(6)$ & 0.142 & 0.318 & 0.115 \\
\hline
\end{tabular}

atoms are numbered as in Table II.
Table IV. Comparison between observed and calculated spacings and structure factors

\begin{tabular}{|c|c|c|c|c|}
\hline$h k l$ & $d_{\mathrm{o}}$ & $d_{\mathrm{c}}$ & $\sqrt{I_{0}}{ }^{8}$ & $\sqrt{I_{\mathrm{c}}^{\mathrm{b}}}$ \\
\hline \multirow{14}{*}{$\left.\begin{array}{lll}1 & 1 & 0 \\
2 & 0 & 0 \\
2 & 1 & 0 \\
0 & 2 & 0 \\
2 & 2 & 0 \\
3 & 1 & 0 \\
1 & 3 & 0 \\
4 & 2 & 0 \\
5 & 1 & 0 \\
5 & 3 & 0 \\
6 & 2 & 0 \\
0 & 6 & 0 \\
7 & 3 & 0 \\
8 & 1 & 0 \\
6 & 4 & 0 \\
1 & 6 & 0 \\
8 & 0 & 0\end{array}\right\}$} & 6.45 & 6.41 & 61 & 41 \\
\hline & 5.30 & 5.32 & 54 & 53 \\
\hline & 4.70 & 4.42 & $v w^{c}$ & 3 \\
\hline & 4.03 & 4.00 & 45 & 72 \\
\hline & 3.25 & 3.21 & 134 & 123 \\
\hline & 2.62 & 2.59 & 71 & 63 \\
\hline & 2.15 & 2.21 & 54 & 43 \\
\hline & 2.05 & 2.06 & 72 & 71 \\
\hline & 1.65 & 1.66 & 32 & 31 \\
\hline & 1.62 & 1.62 & 31 & 24 \\
\hline & & $\begin{array}{l}1.33 \\
1.32\end{array}$ & & \\
\hline & & 1.31 & vw & 15 \\
\hline & 1.31 & $\begin{array}{l}1.33 \\
1.32\end{array}$ & & \\
\hline & & 1.33 & & \\
\hline 111 & 5.02 & 5.00 & 195 & 181 \\
\hline 211 & 4.12 & 3.88 & vw & 9 \\
\hline 121 & 3.33 & 3.40 & 37 & 39 \\
\hline $\left.\begin{array}{lll}2 & 2 & 1 \\
3 & 1 & 1\end{array}\right\}$ & 2.99 & 2.98 & 81 & 96 \\
\hline $\left.\begin{array}{lll}3 & 1 & 1 \\
3 & 2 & 1\end{array}\right)$ & & $\begin{array}{l}3.01 \\
2.51\end{array}$ & & \\
\hline 401$\}$ & 2.49 & 2.51 & 29 & 48 \\
\hline$\left(\begin{array}{lll}0 & 3 & 1\end{array}\right)$ & & 2.53 & & \\
\hline $\left.\begin{array}{lll}4 & 2 & 1 \\
2 & 4 & 1\end{array}\right)$ & 2.14 & $\begin{array}{l}2.14 \\
1.82\end{array}$ & 79 & 80 \\
\hline $\left.\begin{array}{lll}4 & 3 & 1\end{array}\right\}$ & 1.81 & 1.83 & 31 & 27 \\
\hline $\begin{array}{llll}5 & 2 & 1 \\
6 & 4 & 1)\end{array}$ & & 1.83 & & \\
\hline $\left.\begin{array}{lll}0 & 4 & 1 \\
0 & 5 & 1\end{array}\right\}$ & 1.59 & $\begin{array}{l}1.57 \\
1.57\end{array}$ & $v w$ & 14 \\
\hline $\begin{array}{lll}1 & 1 & 2 \\
2 & 0 & 2\end{array}$ & $\begin{array}{l}3.38 \\
3.22\end{array}$ & 3.40 & $\begin{array}{l}37 \\
43\end{array}$ & 38 \\
\hline $\left.\begin{array}{llll}2 & 0 & 2 \\
0 & 2 & 2\end{array}\right)$ & 28 & 2.82 & 31 & \\
\hline $\left.\begin{array}{lll}1 & 2 & 2\end{array}\right\}$ & 2.82 & 2.73 & 31 & 29 \\
\hline $\left.\begin{array}{lll}3 & 1 & 2 \\
2 & 2 & 2\end{array}\right\}$ & 2.51 & $\begin{array}{l}2.51 \\
2.50\end{array}$ & 54 & 36 \\
\hline $\begin{array}{lll}3 & 2 & 2\end{array}$ & & 2.21 & & \\
\hline $\left.\begin{array}{lll}4 & 0 & 2 \\
0 & 3 & 2\end{array}\right\}$ & 2.20 & $\begin{array}{l}2.21 \\
2.22\end{array}$ & 33 & 42 \\
\hline $\begin{array}{lll}0 & 2 & 3\end{array}$ & 2.22 & 2.22 & 32 & 50 \\
\hline $\left.\begin{array}{lll}4 & 0 & 3\end{array}\right\}$ & 1.87 & 1.88 & 24 & 25 \\
\hline $\begin{array}{lll}0 & 3 & 3 \\
5 & 1 & 3\end{array}$ & 1.62 & $\begin{array}{l}1.89 \\
1.63\end{array}$ & 31 & 21 \\
\hline 134$)$ & & 1.58 & & \\
\hline $\left.\begin{array}{lll}3 & 2 & 4 \\
0 & 3 & 4\end{array}\right\}$ & 1.57 & $\begin{array}{l}1.60 \\
1.60\end{array}$ & 25 & 24 \\
\hline $\left.\begin{array}{lll}4 & 0 & 4 \\
3 & 3 & 4\end{array}\right)$ & & 1.60 & & \\
\hline $\left.\begin{array}{lll}4 & 2 & 4 \\
3\end{array}\right\}$ & 1.45 & $\begin{array}{l}1.46 \\
1.48\end{array}$ & 20 & 12 \\
\hline $\left.\begin{array}{lll}5 & 0 & 4\end{array}\right)$ & & 1.46 & & \\
\hline 044 & & 1.41 & & \\
\hline $\left.\begin{array}{lll}1 & 4 & 4 \\
5 & 1 & 4\end{array}\right\}$ & 1.40 & $\begin{array}{l}1.40 \\
1.43\end{array}$ & vw & 6 \\
\hline
\end{tabular}

a The observed structure factors $\sqrt{I_{0}}$ 's were put on the same scale as the $\sqrt{I_{\mathrm{c}}}\left(=\sqrt{m_{\mathrm{c}_{\mathrm{c}}^{2}}}\right)$ 's by setting $\sum k \sqrt{I_{0}}=\sum \sqrt{m F_{\mathrm{c}}^{2}}$, where $k$ is the scale factor and $m$ is the multiplicity.

b $\sqrt{I_{\mathrm{c}}}$ 's of the reflections which overlap on the $\mathrm{X}$-ray fiber photographs are $\sqrt{\sum m F_{\mathrm{c}}^{2}}$.

c vw indicates a reflection which was not estimated because of very weak intensity. 


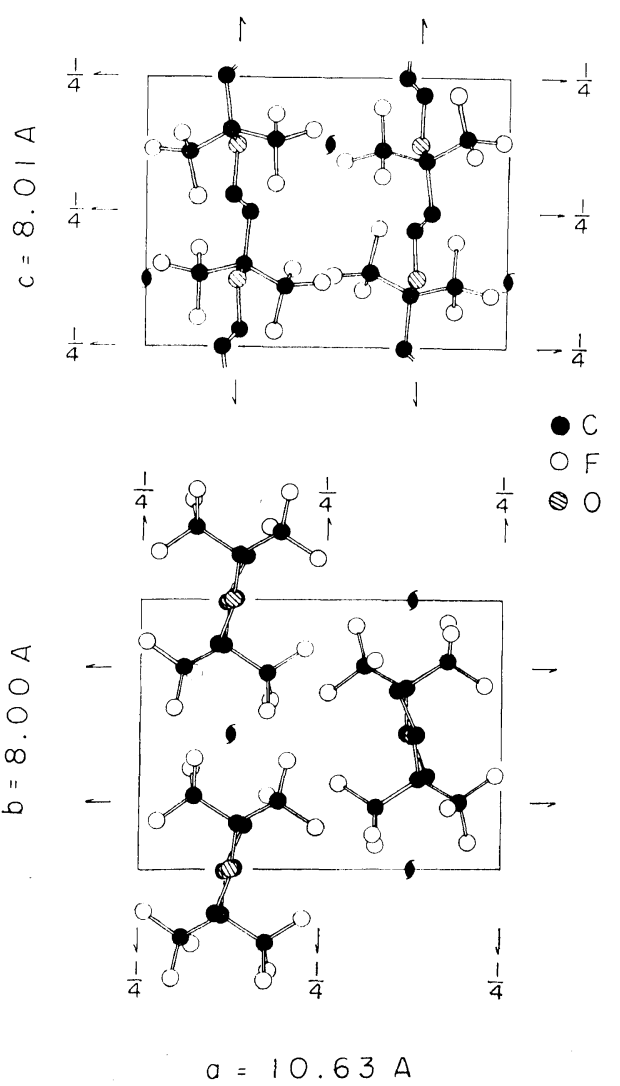

Figure 3. Crystal structure of poly(HFAc-ET).

acceptable van der Waals distances (the closest distance of F...F contact is $2.55 \mathrm{~A}$ ).

\section{RESULTS AND DISCUSSION}

Two of the authors (Y. T. and W. I. $)^{1}$ reported previously by using the NMR method that poly(HFAc-ET) obtained by copolymerization below its critical temperature $\left(-10^{\circ} \mathrm{C}\right)$ is an alternating copolymer. The present X-ray study confirmed definitely that the copolymer obtained by $\gamma$-irradiation of a hexafluoroacetone-ethylene mixture at $-78^{\circ} \mathrm{C}$ has the alternating structure of hexafluoroacetone and ethylene units.

The molecular structure is illustrated in Figure 4 , in which the internal rotation angles are also included. The molecular chain forms a $(2 / 1)$ helix with essentially $(T T T C)_{2}$ conformation. In Table V, the conformation of poly(HFAc-ET)

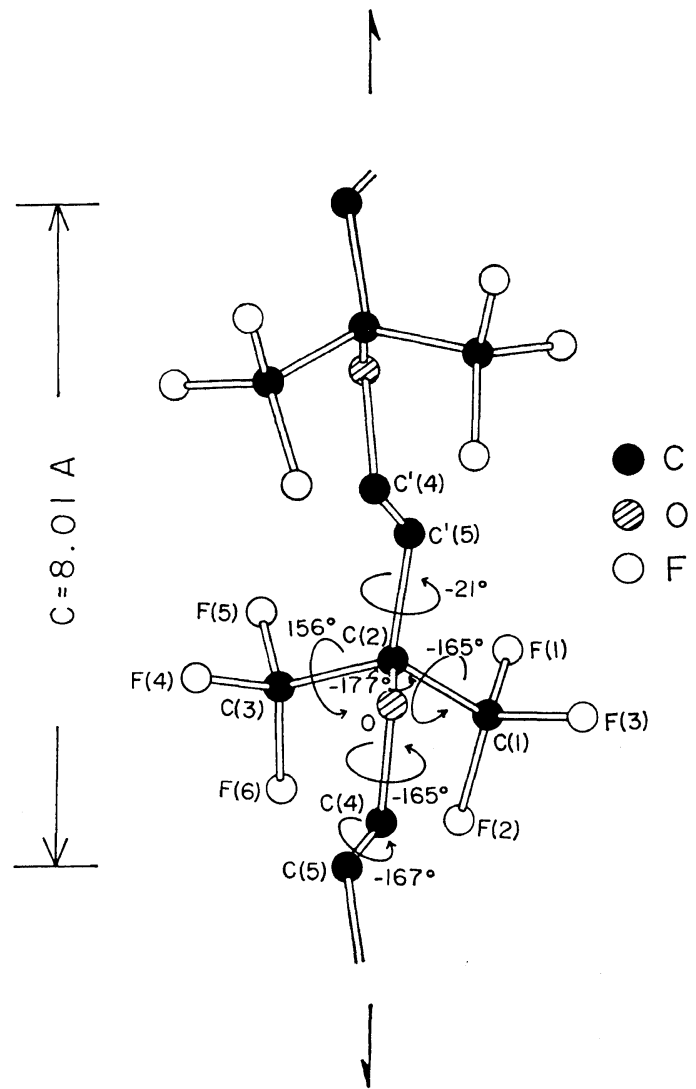

Figure 4. Internal rotation angles of poly(HFAcET).

is compared with those of poly(oxacyclobutane) and poly[3,3-bis(chloromethyl)oxacyclobutane] having the same main chain sequences (-C $\mathrm{C}-\mathrm{C}-\mathrm{O}-)_{n}$. There are three crystalline forms for polyoxacyclobutane and two forms for poly[3,3-bis(chloromethyl)oxacyclobutane]. No polymorphism has yet been found for poly(HFAc-ET).

Considering only one chemical unit, the conformation of poly(HFAc-ET), TTTC, is roughly similar to that of the form II of polyoxacyclobutane, TTTG. The poly(oxacyclobutane) chain has, however, glide symmetry, i.e., TTTGTTT $\bar{G}$, while the poly(HFAc-ET) chain has twofold screw symmetry, $(\text { TTTC })_{2}$. The $(T T T C)_{2} \quad(2 / 1)$ helical conformation of poly(HFAc-ET) is a new conformation found for the $(-\mathrm{C}-\mathrm{C}-\mathrm{C}-\mathrm{O}-)_{n}$ sequence of the main chain. According to a previous con- 
H. Matsubayashi, Y. Chatani, H. Tadokoro, Y. Tabata, and W. Ito

Table V. Conformations of poly(HFAc-ET), Poly(oxacyclobutane), and poly[3,3-bis(chloromethyl)oxacyclobutane]

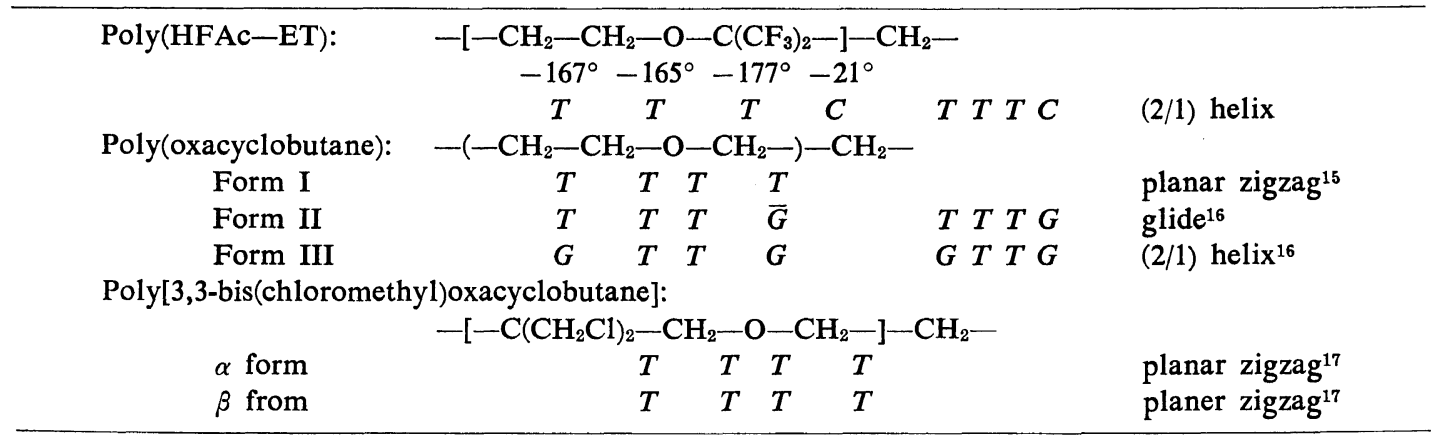

formational analysis, ${ }^{14}$ an isolated polyoxacyclobutane chain of $(T T T G)_{2}$ type is one of four stable ones, whose intramolecular potential energies are nearly equal to one another, and the other three correspond to forms I, II, and III. However, such a twofold helix of polyoxacyclobutane has not yet been found experimentally. The aforementioned internal rotation angle denoted by $\mathrm{C}$ is $-21^{\circ}$, which deviates significantly from the potential minima for the internal rotation about the $\mathrm{C}-\mathrm{C}$ bond, $T, G$, and $\bar{G}$. The starting model III set up from the calculated result of the intramolecular interaction has the closely similar internal rotation angle of $-22^{\circ}$. Therefore, such a deviation would be ascribed to some intramolecular interactions. In Figure 4, if the main chain conformation about the $C^{\prime}(5)-C(2)$ took one of the staggered forms, there might be very close contact of the groups $\mathrm{C}^{\prime}(4) \mathrm{H}_{2} \cdots \mathrm{C}(1) \mathrm{F}_{3}$ or $\mathrm{C}^{\prime}(4) \mathrm{H}_{2} \cdots \mathrm{C}(3) \mathrm{F}_{3}$. These steric hindrances seem to be relaxed by twisting the $C^{\prime}(5)-C(2)$ bond away from the staggered form.

The interatomic distance of the $C(4) \cdots F(6)$ and $C(4) \ldots F(2)$ are too close when all the internal rotation angles of $C^{\prime}(5)-C(2)-O-C(4)$, $\mathrm{O}-\mathrm{C}(2)-\mathrm{C}(3)-\mathrm{F}(5)$, and $\mathrm{O}-\mathrm{C}(2)-\mathrm{C}(1)-\mathrm{F}(1)$ are $180^{\circ}$ and the $\mathrm{C}(3)-\mathrm{F}(6), \mathrm{O}-\mathrm{C}(4)$, and $\mathrm{C}(1)-\mathrm{F}(2)$ bonds are parallel. Variations of the internal rotation angles of the $\mathrm{O}-\mathrm{C}(2)-$ $\mathrm{C}(3)-\mathrm{F}(5)$ and $\mathrm{O}-\mathrm{C}(2)-\mathrm{C}(1)-\mathrm{F}(1)$ from $180^{\circ}$ to $156^{\circ}$ and $-165^{\circ}$, respectively, relax the steric hindrances of the $C(4) \cdots F(6)$ and $C(4) \cdots F(2)$ pairs. In the case of poly(oxacyclobutane), only the conformations close to exact $T, G$, and $\bar{G}$, have been observed, and no unreasonable con- tacts arise from such sequences of conformations because they possess no bulky side groups. By the examination of the interchain atomic distances in the crystal of poly(HFAc-ET) (Figure 3 ), it is found that the molecular chains contact through only the side groups $\left(\mathrm{CF}_{3}\right)$. Therefore, it may be considered that the molecular chain packing of poly(HFAc-ET) is mainly governed by the bulky side groups $\left(\mathrm{CF}_{3}\right)$.

\section{REFERENCES}

1. Y. Tabata, W. Ito, K. Oshima, and Y. Yamamoto, Advan. Chem. Ser., No. 129, 190 (1973).

2. M. Yokouchi, H. Tadokoro, and Y. Chatani, Macromolecules, 7, 769 (1974).

3. H. Tadokoro, K. Tai, M. Yokoyama, and M. Kobayashi, J. Polym. Sci., Polym. Phys. Ed., 11, 825 (1973).

4. A. Bondii, J. Phys. Chem., 68, 441 (1964).

5. J. Ketelaar, "Chemical Constitution," Elsevier Publ. Co., New York, N.Y., 1958, p. 90.

6. R. A. Scott and H. A. Scheraga, J. Chem. Phys., 42, 2209 (1965).

7. K. S. Pitzer, Advan. Chem. Phys., 2, 59 (1959).

8. C. P. Smyth, "Dielectric Behaviour and Structure," McGraw-Hill, New York, N.Y., 1955, p 244.

9. R. Hasegawa, Doctoral Thesis, Osaka University, 1971.

10. R. Hasegawa, T. Takahashi, Y. Chatani, and H. Tadokoro, Polym. J., 3, 600 (1972).

11. L. E. Sutton, et al., "Tables of Interatomic Distances and Configuration in Molecules and Ions," The Chemical Society, London, 1958.

12. S. Arnott and A. J. Wonacott, Polymer, 7, 157 (1966).

13. Y. Takahashi, T. Sato, H. Tadokoro, and Y. 


\section{Structure of Hexafluoroacetone-Ethylene Copolymer}

Tanaka, J. Polym. Sci., Polym. Phys. Ed., 11, 16. H. Tadokoro, Y. Takahashi, Y. Chatani, and 233 (1973).

H. Kakida, Makromol. Chem., 109, 96 (1967).

14. K. Tai and H. Tadokoro, Macromolecules, 7, 17. Y. Takahashi, H. Tsugaya, and H. Tadokoro, 507 (1974).

15. H. Kakida, D. Makino, Y. Chatani, M. Kobayashi, and H. Tadokoro, ibid., 3, 569 (1970). 19th Macromol, Symp. Polym. Soc. Japan, Kyoto, Preprints, 1970, p 743. 